04

\title{
Применение термообработки при формировании рельефно-фазовых голографических структур на бихромированном желатине
}

\author{
(C) Н.М. Ганжерли ${ }^{1}$, С.Н. Гуляев ${ }^{2}$, И.А. Маурер ${ }^{1}$ \\ ${ }^{1}$ ФТИ им. А.Ф. Иофрфе, \\ 194021 Санкт-Петербург, Россия \\ ${ }^{2}$ Санкт-Петербургский политехнический университет Петра Великого, \\ 195251 Санкт-Петербург, Россия \\ e-mail: nina.holo@mail.ioffe.ru
}

Поступила в редакцию 28.05.2020 г.

В окончательной редакции 28.05.2020 г.

Принята к публикации 16.06.2020 г.

Предложен новый способ формирования рельефно-фазовой голографической структуры на слоях бихромированного желатина (БХЖ). В основе метода лежит применение двух видов альтернативного воздействия на желатин: структурирования с помощью избирательного светового дубления когерентным излучением $\mathrm{He}-\mathrm{Cd}$-лазера и деструкции коротковолновым УФ излучением. Для получения высокоэффективных голографических рельефных структур в области высоких пространственных частот, вплоть до $1500 \mathrm{~mm}^{-1}$, ранее была предложена сокращенная по времени водная обработка образцов, прерываемая изопропаноловой ванной. В настоящей работе предлагается отказаться от водной обработки слоев БХЖ и заменить ее нагревом образца во время обработки коротковолновым УФ излучением. В ходе экспериментов получено устойчивое возрастание дифракционной эффективности независимо от пространственной частоты и толщины слоя БХЖ, что объясняется образованием рельефной голографической структуры вследствие испарения и усадки деструктированных УФ излучением участков желатина под действием высокой температуры.

Ключевые слова: голографические дифракционные решетки, бихромированный желатин, коротковолновое УФ излучение, структурирование, деструкция, поверхностный рельеф, термическая обработка.

DOI: $10.21883 /$ OS.2020.10.50022.158-20

\section{Введение}

Получение высокоэффективных рельефно-фазовых голографических структур на содержащих желатин средах подробно описано в $[1,2]$. При этом ключевой операцией обработки является освещение слоев коротковолновым УФ излучением ртутно-кварцевой лампы, которое приводит к фотодеструкции желатина и переводит его в растворимое в воде состояние. Формирование рельефной структуры на поверхности желатинового слоя в соответствии с первоначально записанной интерференционной картиной зависит от типа светочувствительной содержащей желатин среды. Для галоидосеребряной фотоэмульсии наличие серебряного изображения интерференционной картины модулирует степень облучения и фотодеградации верхних слоев фотоматериала УФ излучением. Для БХЖ интерференционная картина первоначально регистрируется в виде переменной задубленности слоя по всей толщине. Поскольку более задубленные участки желатина сопротивляются разрушающему воздействию УФ излучения более эффективно, то действие облучения на поверхностный слой желатина, так же как и для галоидосеребряной фотоэмульсии, модулировано в соответствии с интерференционной картиной голограммы. В обоих случаях поверхностный рельеф образуется за счет вымывания (травления) наиболее разрушенных участков желати- на водой. Однако наличие водной обработки является фактором, препятствующим получению необходимой глубины поверхностного рельефа на пространственных частотах голографической структуры, превышающих 200-300 mm $\mathrm{mm}^{-1}$ [3]. Это обстоятельство вызвано тем, что желатин в водных растворах набухает, размягчается, и при сушке мокрого коллоида силы поверхностного натяжения разглаживают поверхностный рельеф. Для слоев БХЖ проблему удалось решить, сократив время водной обработки до минимума $(10 \mathrm{~s})$ и введя процедуру быстрого обезвоживания с помощью изопропанола $[4,5]$. Это позволило получить рельефно-фазовые голографические решетки с пространственной частотой $1500 \mathrm{~mm}^{-1}$ и высокой дифракционной эффективностью (ДЭ), превышающей 50\%.

В настоящей работе предложен вариант обработки слоев БХЖ, который на стадии формирования поверхностного рельефа голографической структуры исключает водную процедуру вообще. Действительно, удаление разрушенных коротковолновым УФ излучением участков желатина можно осуществить не только погружая слой БХЖ в воду, но и используя для этой цели сильный нагрев, поскольку известно, что при температурах, превышающих $150^{\circ} \mathrm{C}$, желатин начинает разлагаться с образованием летучих компонентов.

В более ранних зарубежных работах были попытки использовать термическое разложение и удаление 
желатина с подложки для создания рельефных структур (без применения коротковолнового УФ излучения). Авторы работы [6] использовали галоидосеребряную фотоэмульсию, на которой методами фотолитографии регистрировалась бинарная пространственная структура. При воздействии на образцы потоком горячего воздуха $\left(375-425^{\circ} \mathrm{C}\right)$ в течение $15-30 \mathrm{~min}$ удавалось полностью удалить желатин из мест, свободных от соединений серебра, в то время как участки, содержащие серебряное изображение, оставались практически нетронутыми. В указанной работе авторам удалось получить на фотоэмульсии Kodak High Resolution Plate с первоначальной толщиной $6 \mu \mathrm{m}$ бинарные структуры с пространственной частотой порядка нескольких десятков $\mathrm{mm}^{-1}$. В работе [7] для записи голографических решеток с низкой пространственной частотой $7 \mathrm{~mm}^{-1}$ использовалось когерентное ИК излучение $\mathrm{CO}_{2}$-лазера с плотностью мощности порядка $25 \mathrm{~W} / \mathrm{cm}^{2}$. При экспонировании в течение нескольких секунд на желатиновых пленках толщиной 20-50 $\mu \mathrm{m}$, закрепленных в специальных оправах, регистрировались рельефно-фазовые решетки с максимальной ДЭ в 30\%, близкой к теоретическому пределу для тонких фазовых голограмм при длине волны считывающего пучка $\lambda=0.63 \mu \mathrm{m}$.

В отношении применения термической обработки для слоев БХЖ при их облучении УФ излучением можно сказать, что процесс теплового разложения и испарения желатина должен идти более эффективно в участках, подвергшихся наиболее сильному воздействию коротковолнового УФ излучения, т.е. в наименее задубленных участках слоя БХЖ, соответствующих минимумам интерференционной картины голограммы. Эти участки будут впадинами формирующегося при термической обработке поверхностного рельефа. Поскольку сухой желатин при высоких температурах обладает большой вязкостью и ведет себя скорее как твердое тело, а не жидкость или гель, предполагается, что новую, предложенную в данной работе, методику обработки слоев БХЖ можно применить и для формирования рельефных голографических структур с высокой пространственной частотой, превышающей $1000 \mathrm{~mm}^{-1}$.

\section{Методика эксперимента}

Для осуществления термической обработки слоев БХЖ во время облучения УФ излучением была создана специальная установка. Обрабатываемый образец помещался на массивный электрический нагреватель, на который подавалось переменное напряжение в пределах $0-220 \mathrm{~V}$. Изменяя питающее напряжение, можно было регулировать температуру нагревателя в пределах $20-200^{\circ} \mathrm{C}$. Тепловой контакт между образцом и нагревателем обеспечивался с помощью теплопроводящей пасты. В качестве источника коротковолнового УФ излучения использовалась ртутная лампа ДРТ-220 электрической мощностью $250 \mathrm{~W}$. Промежуток между

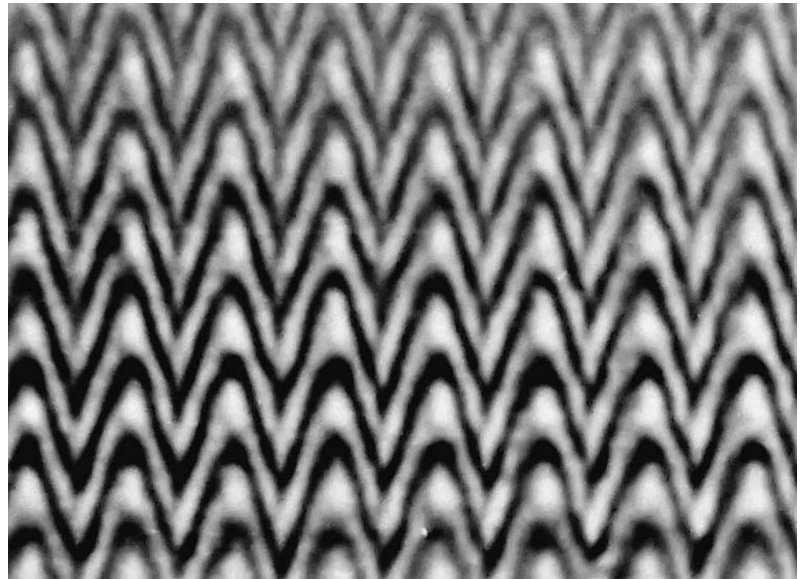

Рис. 1. Интерферограмма поверхности голографической решетки с пространственной частотой $250 \mathrm{~mm}^{-1}$ после термической обработки и УФ облучения фотоэмульсии.

лампой и поверхностью образца составлял $8 \mathrm{~cm}$. Для охлаждения ртутной лампы применялся вентилятор, создававший поток воздуха между лампой и образцом. Калибровка и настройка установки осуществлялась с помощью стеклянных фотопластинок, покрытых галоидосеребряной фотоэмульсией. Для экспериментов использовались пластинки Микрат ВР-Л и ПФГ-01 с толщиной фотоэмульсии $T=6-14 \mu \mathrm{m}$, на которых ранее с помощью стандартных процессов проявления и фиксирования были зарегистрированы амплитудные голографические структуры типа решеток или зонных пластинок Френеля. Указанные голограммы обладали большой оптической плотностью $D$, превышающей единицу, т. е. представляли собой достаточно темные объекты на просвет.

В табл. 1 представлены параметры обработки и характеристики голографических структур. Высота поверхностного рельефа $h$, как полный перепад между гребнями и впадинами периодической структуры, определялась по интерферограммам, полученным с помощью микроинтерферометра МИИ-4 (рис. 1).

Высота рельефа бинарной структуры, приведенной в табл. 1, определялась как разница толщин фотоэмульсионного слоя в облученных и не облученных УФ излучением местах. Для задержки УФ излучения использовался специальный экран.

Эксперименты позволили установить, что с ростом температуры нагревателя вплоть до $170^{\circ} \mathrm{C}$ глубина конечного рельефа заметно возрастает. В интервале температур нагревателя $170-190^{\circ} \mathrm{C}$ прирост глубины конечного рельефа замедляется, а начиная со $190^{\circ} \mathrm{C}$ глубина конечного рельефа падает, и на образцах появляются участки, покрытые трещинами и искажениями поверхности желатинового слоя.

Как видно из табл. 1, высота поверхностного рельефа, получаемого в результате термической обработки низкочастотных (менее $250 \mathrm{~mm}^{-1}$ ) голографических структур, 
Таблица 1. Параметры голографических рельефных структур на галоидосеребряной фотоэмульсии

\begin{tabular}{c|c|c|c|c}
\hline $\begin{array}{c}\text { Тип голографической структуры } \\
\text { и пространственная частота, } \\
\mathrm{mm}^{-1}\end{array}$ & $\begin{array}{c}\text { Начальный } \\
\text { рельеф } h, \\
\mu \mathrm{m}\end{array}$ & $\begin{array}{c}\text { Температура нагрева- } \\
\text { тельного элемента, } \\
{ }^{\circ} \mathrm{C}\end{array}$ & $\begin{array}{c}\text { Время тепловой обработки } \\
\text { и облучения УФ излучением, } \\
\text { min }\end{array}$ & $\begin{array}{c}\text { Конечный } \\
\text { рельеф } h, \\
\mu \mathrm{m}\end{array}$ \\
\hline Бинарная структура, 0 & 0 & 175 & 100 & 1.37 \\
\hline Зонная пластинка Френеля, 0-40 & $<0.3$ & 175 & 90 & 0.80 \\
\hline Решетка*, 110 & $<0.1$ & $190^{*}$ & $30^{*}$ & 0.55 \\
\hline Решетка, 200 & $<0.15$ & 175 & 90 & 0.60 \\
\hline Решетка, 250 & $<0.15$ & 170 & 90 & 0.40
\end{tabular}

Примечание. * Эти данные относятся к более ранней работе [8], в которой термическая обработка амплитудной голографической структуры, записанной на фотоэмульсии Микрат ВР-Л, осуществлялась в термостате при температуре $190^{\circ} \mathrm{C}$ после УФ облучения образца.

составляет величину порядка длины волны видимого света, что вполне достаточно для получения высоких значений ДЭ голограмм, работающих на пропускание (см., например, [2], стр. 8). Однако использовать описанные в табл. 1 голографические структуры в качестве дифракционных элементов невозможно из-за их большой оптической плотности.

Проведенные предварительные эксперименты с фотоэмульсионными слоями, подвергшимися одновременно тепловой обработке и УФ облучению, позволили установить ориентировочные значения оптимальных температур нагревателя и времени обработки образцов, что было использовано в последующих экспериментах по созданию высокочастотных голографических решеток на слоях БХЖ.

\section{Результаты}

Для проведения экспериментов по термической обработке образцов на БХЖ мы располагали слоями разной толщины, на которых с помощью $\mathrm{He}-\mathrm{Cd}$-лазера $(\lambda=0.44 \mu \mathrm{m})$ были записаны голографические решетки по симметричной оптической схеме. Приготовление слоев БХЖ и методика регистрации первичной голографической структуры осуществлялись стандартными методами и достаточно подробно изложены, например, в $[1,9]$. Так же как и для галоидосеребряных фотоэмульсий, для слоев БХЖ термическая обработка образцов одновременно сочеталась с их облучением УФ излучением. При этом удаление фотодеструктированного желатина нагреванием преимущественно из наименее задубленных мест первичной голографической структуры давало доступ УФ излучению к более глубоким слоям желатина и в итоге способствовало получению большей глубины поверхностного рельефа.

Время термической обработки для большинства образцов составляло примерно $90 \mathrm{~min}$. Температура нагревателя была выбрана несколько меньше, чем для экспериментов с галоидосеребряными фотоэмульсиями
Таблица 2. Коэффициент пропускания образцов по интенсивности для длины волны $\lambda=0.63 \mu \mathrm{m}$

\begin{tabular}{c|c|c}
\hline Образец & $\begin{array}{c}\text { Толщина образца* } \\
\text { вне области решетки, } \mu \mathrm{m}\end{array}$ & $\begin{array}{c}\text { Коэффициент } \\
\text { пропускания, \% }\end{array}$ \\
\hline 1 & 5.6 & 85 \\
2 & 5.7 & 84 \\
3 & 12.0 & 84 \\
4 & 14.7 & 83 \\
5 & 60.0 & 77
\end{tabular}

Примечание. Указанная толщина образца не учитывает толщину стеклянной подложки.

$\left(\approx 163^{\circ} \mathrm{C}\right)$, из опасения получить чрезмерное потемнение слоев желатина из-за термического разложения. В табл. 2 приведены коэффициенты пропускания образ-

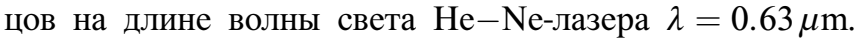
Данные говорят о том, что в диапазоне толщин 5-15 $\mu \mathrm{m}$ степень потемнения образцов незначительна, и лишь для толщины в несколько десятков микрометров (образец 5) поглощение света, вызванное термической обработкой $(\approx 14 \%)$, становится больше потерь света на френелевские отражения $(\approx 8-10 \%)$.

Основным измеряемым параметром для высокочастотных голографических решеток являлась ДЭ, которая определялась как отношение интенсивности света в первом порядке дифракции к интенсивности падающего пучка. В качестве освещающего пучка использовалось излучение $\mathrm{He}-\mathrm{Ne}$-лазера с длиной волны $\lambda=0.63 \mu \mathrm{m}$, которое падало на образец под углом, примерно соответствующем условию Брэгга. На рис. 2 представлены зависимости ДЭ $\eta$ образцов до и после термической обработки и УФ облучения от времени экспонирования слоев БХЖ $t_{\mathrm{He}-\mathrm{Cd}}$ когерентным излучением $\mathrm{He}-\mathrm{Cd}$ лазера (кривые 1 и 2 соответственно). Все образцы содержали голографические решетки с высокой пространственной частотой $1500 \mathrm{~mm}^{-1}$, кроме образца № 5 с повышенной толщиной около $60 \mu \mathrm{m}$, решетка которого имела пространственную частоту $220 \mathrm{~mm}^{-1}$. 

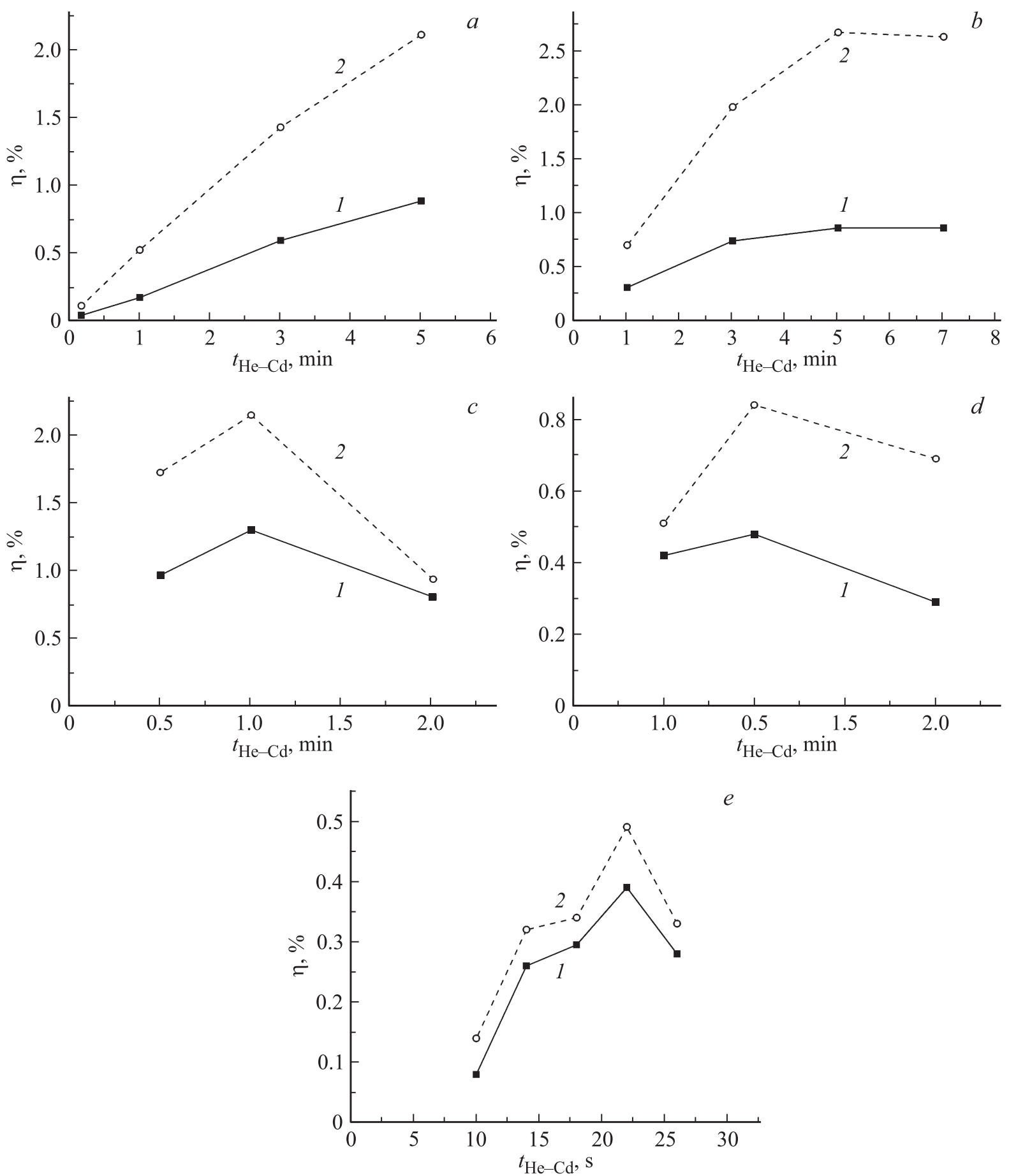

Рис. 2. Зависимости ДЭ образцов $\eta$ до (кривая 1 ) и после (кривая 2) термической обработки и УФ облучения. Пространственная частота $1500 \mathrm{~mm}^{-1}(a),(b),(c),(d) ; 220 \mathrm{~mm}^{-1}(e)$. Толщины образцов указаны в табл. 2.

Как видно из рисунка, все образцы вне зависимости от толщины и пространственной частоты после проведения термической обработки демонстрируют увеличение ДЭ, наиболее сильное для образца № 2 (в 3.1 раза). Исходя из гипотез и экспериментальных фактов, изложенных в предыдущих разделах, мы связываем такое значительное увеличение ДЭ с формированием поверхностной рельефной структуры.

\section{Заключение}

Полученное увеличение ДЭ образцов пока недостаточно для практического применения голографических структур на слоях БХЖ, прошедших термическую обработку и одновременное воздействие коротковолнового УФ излучения. Однако проведенные эксперименты намечают пути решения данной проблемы. Это, во-первых, 
применение первичных голографических структур на БХЖ, зарегистрированных с гораздо большим контрастом, чем у использованных в данной работе образцов. Во-вторых, переход к более тонким образцам, вплоть до толщин слоя БХЖ порядка $2 \mu \mathrm{m}$ и менее, и отсюда возможность повышения температуры термической обработки без опасения чрезмерного потемнения образцов.

\section{Конфликт интересов}

Авторы заявляют, что у них нет конфликта интересов. Настоящая статья не содержит каких-либо исследований с использованием людей и животных в качестве объектов.

\section{Список литературы}

[1] Ганжерли Н.М., Гуляев С.Н., Маурер И.А. // Опт. и спектр. 2018. T. 125. N 1. C. 62; Ganzherli N.M., Gulyaev S.N., Maurer I.A. // Opt. Spectrosc. 2018. V. 125. N 1. P. 65. doi 10.21883/OS.2018.07.46268.73-18

[2] Calixto S., Ganzherli N., Gulyaev S., Figueroa-Gerstenmaier S. // Molecules. 2018. V. 23. N 8. P. 2064. doi 10.3390/molecules 23082064

[3] Гуляев С.Н. // Научно-технические ведомости СПбГПУ. Основной выпуск. 2008. N 3 (59). С. 105-114

[4] Ганжерли Н.М., Гуляев С.Н., Маурер И.А., Хазвалиева Д.Р. // Письма в ЖТФ. 2019. Т. 45. N 12. C. 30; Ganzherli N.M., Gulyaev S.N., Maurer I.A., Khazvalieva D.R. // Technical Physics Lett. 2019. V. 45. N 12. P. 613. doi 10.1134/S1063785019060245

[5] Ганжерли Н.М., Гуляев С.Н., Маурер И.А., Архипов А.В. // Автометрия. 2020. Т. 56. N 12. С. 92. doi 10.15372/AUT20200210

[6] Chand N. Патент US № 3639 125. 1972.

[7] Calixto S. // Applied Optics. 1988. V. 27. N 10. P. 1977

[8] Гуляев С.Н. Рельефно-фазовые голограммы на фотоэмульсионных слоях, облученных ультрафиолетовым излучением. Дис. канд. физ.-мат. наук. СПб., 2006. 196 с.

[9] Ганжерли Н.М., Гуляев С.Н., Маурер И.А. // Письма в ЖТФ. 2016. Т. 42. В. 19. С. 26-30; Ganzherli N.M., Gulyaev S.N., Maurer I.A. // Techn. Phys. Lett. 2016. V. 42. N 10. P. 988. doi 10.1134/S1063785016100060 